\title{
Prognostic Impact of MGMT Promoter Methylation in Glioblastoma - A Systematic Review
}

\author{
Quintino Giorgio D’Alessandris ${ }^{1}$, Nicola Montano', Luigi Maria Larocca², Giulio Maira ${ }^{1}$ and Roberto Pallini ${ }^{1 *}$
}

${ }^{1}$ Institutes of Neurosurgery, Università Cattolica del Sacro Cuore, Largo Agostino Gemelli, 8, Rome, Italy

${ }^{2}$ Pathology, Università Cattolica del Sacro Cuore, Largo Agostino Gemelli, 8, Rome, Italy

\begin{abstract}
MGMT promoter methylation is currently considered the main prognostic biomarker in glioblastoma, yet some concerns remain about its actual impact on outcome. The aim of the present study was to analyze literature data on this topic. Therefore, a systematic review and analysis of recently published glioblastoma cohorts examining the relationship between MGMT methylation and prognosis was performed. We found that only 19/28 studies $(68 \%)$ confirmed the prognostic value of MGMT methylation and/or its role in predicting response to temozolomide. In these studies, however, the population showed significantly lower rates of unfavorable prognosticators as compared with studies where MGMT methylation was not prognostic/predictive. Moreover, studies demonstrating a better prognosis for MGMT methylated cases had significantly lower rates of deaths at 3 and 6 months. Multivariate analysis showed that the 3-month and 6-month deaths are significantly associated with the prognostic/predictive value of MGMT methylation, and that the percent of MGMT methylated tumors and of patients treated with alkylating drugs trend towards statistical significance if modeled with the 6-month but not with the 3-month mortality rate. These results suggest that the paucity of short-term survivors may represent a bias in studies focusing on MGMT methylation and prognosis, and that a temporal threshold may be necessary in order to demonstrate the clinical benefit of MGMT promoter methylation.
\end{abstract}

Keywords: Glioblastoma; MGMT; Survival; Epigenomics; Alkylating antineoplastic agents

\begin{abstract}
Abbreviations: Alkyl: Treated with Alkylating Drugs; CI: Confidence Interval; Coeff: Coefficient; Debulk Surg: Debulking Surgery; ECOG: Eastern Cooperative Oncology Group Performance Status; EORTC: European Organisation For Research and Treatment Of Cancer; GBM: Glioblastoma; KPS: Karnofsky Performance Status; Meth: Methylated ; MGMT: $\mathrm{O}^{6}$-Methylguanine DNA-Methyltransferase ; NA: Not Available or Not Applicable; NCIC: National Cancer Institute of Canada; OR: Odds Ratio; Pros: Prospective; PS: Performance Status; Pts: Patients; Ret: Retrospective; SE: Standard Error; TMZ: Temozolomide
\end{abstract}

\section{Introduction}

$\mathrm{O}^{6}$-methylguanine DNA-methyltransferase (MGMT) is a DNArepair protein that removes alkyl groups from the $\mathrm{O}^{6}$ position of guanine and therefore blunts the cytotoxic effect of alkylating drugs, including temozolomide (TMZ) [1,2]. Epigenetic silencing of the MGMT gene through promoter methylation is associated with diminished DNArepair activity [2]; this event has been linked with a better response to alkylating drugs and with an improved outcome in malignant glioma [1]. The 2-year analysis of the milestone multicenter randomized EORTC-NCIC trial confirmed the prognostic and predictive role of MGMT promoter methylation for response to TMZ in glioblastoma (GBM) [3]. The 5-year analysis of survival data from the same trial confirmed the prognostic role of MGMT promoter methylation but resized its predictive value for response to TMZ [4]. Recently, the prognostic role of MGMT promoter methylation in GBM has been confirmed in a large phase III trial comparing standard-dose and doseintensified TMZ in newly diagnosed GBM [5].

Several issues have been raised on the actual role of MGMT promoter methylation in GBM, including the choice of the method to assess the methylation status [6] and the relationship between MGMT promoter methylation and reduced MGMT protein expression [7-
9]. Apart from technical problems, however, an accurate analysis of the pertinent literature shows that the prognostic and predictive role of MGMT promoter methylation in GBM was not confirmed in a substantial number of cohorts [9-18]. The aim of the present study was to review published series that addressed the issue whether MGMT promoter methylation status may be correlated with survival of GBM patients.

\section{Materials and Methods}

\section{Articles search}

A search was performed in Pubmed database (http://www.ncbi. nlm.nih.gov/pubmed) using as keywords, "glioblastoma", "MGMT promoter methylation", "survival analysis", and as search operator "AND". The search was limited to articles published after 2005, i.e. the year in which TMZ chemotherapy began the standard for treatment of GBM patients [19]. This search retrieved 107 articles; through alternative searches, 2 more articles were found [11,20]. Of these 109 articles, 82 were excluded from analysis because of the followings, 1) data were not original $(N=17) ; 2)$ Kaplan-Meier survival curves were not available $(N=21) ; 3)$ series included less than 30 patients $(N=10) ; 4)$ GBM patients were categorized using non-canonical criteria $(N=23) ; 5)$ lower grade gliomas $(N=3)$ and/or other tumors $(N=3)$ were included;

*Corresponding author: Roberto Pallini, Institute of Neurosurgery, Università Cattolica del Sacro Cuore, Largo Agostino Gemelli, 8, Rome, 00168, Italy, Tel: +39 0630154120, +39 0630154358; Fax: +39 063051343; E-mail: pallini@rm.unicatt.it

Received March 05, 2014; Accepted March 27, 2014; Published March 31, 2014

Citation: D'Alessandris QG, Montano N, Larocca LM, Maira G, Pallini R (2014) Prognostic Impact of MGMT Promoter Methylation in Glioblastoma - A Systematic Review. J Cancer Sci Ther 6: 136-141. doi:10.4172/1948-5956.1000261

Copyright: (c) 2014 D'Alessandris QG, et al. This is an open-access article distributed under the terms of the Creative Commons Attribution License, which permits unrestricted use, distribution, and reproduction in any medium, provided the original author and source are credited. 
6) only in vitro or in vivo data were reported $(N=3)$, and 7) patients did not receive adjuvant radio-chemotherapy $(N=2)$. We also included the recently published results of the phase III trial comparing standarddose and dose-dense adjuvant TMZ for newly diagnosed GBMs (NCT00304031) [5]. Therefore, our final analysis included 28 studies, in which survival data were analyzed in relation with the MGMT methylation status.

\section{Articles analysis}

From the 28 studies addressing the question of the correlation between MGMT promoter methylation and prognosis, the following data were extrapolated, number of GBM cases, type of study (retrospective, prospective, trial), median age of patients (or mean age, if median not available), percent of patients with good performance status, percent of patients who underwent debulking $v s$ biopsy surgery, percent of patients treated with TMZ or other alkylating agents, percent of cases in whom MGMT promoter methylation status was assessed, percent of cases with methylated MGMT promoter, and percent of deaths at 3 and 6 months from diagnosis of GBM. Whenever possible, this analysis was restricted to the subset of patients treated with radiotherapy plus adjuvant alkylating chemotherapy and in whom MGMT methylation status was assessed. Good performance status was defined as ECOG 0 or 1 or Karnofsky performance status $($ KPS $)>70$. Debulking surgery was defined as any surgical operation for tumor removal excluding biopsy. Extrapolation of 3-month and 6-month survival data was performed based on the Kaplan-Meier curves. In those studies where overall survival was calculated from the date of randomization, deaths at 3 and 6 months from diagnosis were calculated based on study protocol details.

\section{Statistical analysis}

Comparison of clinical parameters (3-month and 6-month death rate, percent of retrospective studies, percent of patients with good performance status, percent of patients treated with debulking surgery, percent of patients treated with alkylating drugs, and percent of tumors with methylated MGMT promoter) among the different study groups was performed using the Chi-square test. Comparison of median age was performed using the Student's $t$-test. A multivariate logistic regression model was used to estimate the odds ratio of the prognostic/predictive significance of MGMT promoter methylation while adjusting for baseline variables that included number of cases, age, percent of methylated MGMT promoter, type of study (whether retrospective or not), treatment with alkylating drugs and deaths at 3 and at 6 months. The results are reported as 2 -sided $P$ values with $95 \%$ confidence intervals. Differences were considered significant at $P<0.05$. Statistical analyses were conducted using Stat View version 5 software (SAS Institute Inc., Cary, NC).

\section{Results}

Out of 28 studies that addressed the question of the correlation between MGMT promoter methylation and prognosis of GBM patients, 19 articles (68\%) showed a direct relationship between the two variables (MGMT methylation predictive/prognostic of better prognosis), whereas in 9 articles (32\%) such a relationship was not demonstrated (MGMT methylation no predictive/prognostic) (Table 1). The size of the study did not differ significantly between studies with MGMT predictive/prognostic and studies with MGMT not predictive/ prognostic $(136.4 \pm 168.1$ patients in the first group vs. $82.9 \pm 32.8$ patients in the second group, mean+standard deviation; $P=0.6759$,
Mann-Whitney $U$ test; $63.2 \%$ of studies with $\geq 70$ patients in the first group vs. 55.6\% in the second group; $P>0.9999$, Fisher's Exact Test). All the studies were analyzed for clinical variables of known prognostic value, like the age of patients, performance status, type of surgery (debulking $v s$ biopsy), and for additional variables including the type of study (whether retrospective or not), adjuvant treatment with alkylating drugs, percent of MGMT methylated tumors, and 3-month and 6-month death rates. We found that only age was homogeneously distributed between studies where MGMT methylation was predictive/ prognostic and those where MGMT methylation was not predictive/ prognostic, whereas all the remaining parameters were significantly different (Table 2). In particular, clinical variables with known unfavorable prognostic value, like poor performance status and biopsy surgery, were significantly higher in studies where MGMT methylation was not predictive/prognostic (Table 2).

We then established a multivariate logistic regression analysis that accounted for number of patients, age, percent of MGMT methylated tumors, type of study, treatment with alkylating drugs, and either 3 -month or 6-month death rate. This analysis showed that both deaths at 3 and at 6 months were significantly associated with the predictive/ prognostic significance of MGMT promoter methylation in a study cohort ( $P=0.0479$ and 0.0151 , respectively; Tables 3 and 4$)$. In the model accounting for 6-month death rate, both the percent of MGMT methylated tumors and the percent of cases treated with alkylating drugs trended towards statistical significance $(P=0.0646$ and 0.0536 , respectively; Table 4 ).

In order to determine the specific weight of early deaths in MGMTrelated prognosis, we assessed in each study the percent of deaths at 3 months both in MGMT methylated cases and in MGMT unmethylated cases (Table 5). Interestingly, we found that the 3-month mortality rate was significantly different both between the methylated cases of predictive/prognostic and the methylated cases of no predictive/ prognostic series, and between the unmethylated cases of predictive/ prognostic and the unmethylated cases of no predictive/prognostic series ( $P=0.0003$ and 0.001 , respectively; Table 6$)$.

\section{Discussion}

\section{MGMT promoter methylation and GBM prognosis: state-of- art}

Since data from the milestone EORTC-NCIC trial became available [3], MGMT promoter methylation status has been regarded as the main prognostic biomarker for GBM [4,6]. There is a large number of publications that support this statement [3,5,20-36]. Methylation of the promoter of the MGMT gene is believed to result in lower levels of MGMT protein and therefore in a reduced removal of promutagenic alkyl adducts from DNA, hence strengthening the efficacy of alkylating drugs including TMZ $[1,2]$. However, there are some concerns on this theory. First, the association between MGMT promoter methylation and reduced MGMT protein expression in GBM is still a matter of debate in literature $[7,8,9]$. Moreover, issues have recently been raised on the reliability of methods used for assessing the MGMT promoter methylation status, that include, i) low precision of current techniques, ii) heterogeneous methylation of cytosine-guanine dinucleotides in the gene's promoter region, and iii) contamination of macrodissected specimens by nontumor cells [6].

\section{Findings of the current study}

Here, we performed a systematic review of the literature in order 
Citation: D'Alessandris QG, Montano N, Larocca LM, Maira G, Pallini R (2014) Prognostic Impact of MGMT Promoter Methylation in Glioblastoma - A Systematic Review. J Cancer Sci Ther 6: 136-141. doi:10.4172/1948-5956.1000261

\begin{tabular}{|c|c|c|c|c|c|c|c|c|c|c|}
\hline \multirow{2}{*}{ Authors \& Year } & \multirow{2}{*}{$N$ cases } & \multirow{2}{*}{ Type of study } & \multirow{2}{*}{$\begin{array}{l}\text { Age } \\
\text { (yrs) }\end{array}$} & \multirow{2}{*}{ Good PS (\%) } & \multirow{2}{*}{ Debulk surg (\%) } & \multirow{2}{*}{ Alkyl (\%) } & \multirow{2}{*}{ MGMT assayed (\%) } & \multirow{2}{*}{ MGMT meth (\%) } & \multicolumn{2}{|c|}{ Deaths (\%) } \\
\hline & & & & & & & & & 3 mos & $6 \mathrm{mos}$ \\
\hline \multicolumn{11}{|c|}{ MGMT methylation prognostic/predictive } \\
\hline Balañà et al., 2011 [21] & 70 & ret $^{\mathrm{a}, \mathrm{b}}$ & 64 & 88.6 & 85.7 & 98.6 & 100 & 38.6 & 5.7 & 17.1 \\
\hline Brandes et al., 2008 [22] & 103 & triala $^{\mathrm{a}, \mathrm{b}}$ & 53 & 92 & 99 & 100 & 100 & 35 & 0 & 1.9 \\
\hline Cao et al., 2009 [23] & 73 & ret $^{a}$ & 55 & 54.2 & 91.6 & 100 & 100 & 60.3 & 1.4 & 8.2 \\
\hline Crinière et al., 2007 [24] & 77 & ret $^{a}$ & 58 & 63 & NA & 100 & 100 & 58.4 & 1.3 & 6.5 \\
\hline Dunn et al., 2009 [20] & 109 & ret $^{\mathrm{a}, \mathrm{b}}$ & 55 & 84 & 76 & 100 & 100 & 53.2 & 3.7 & 15.6 \\
\hline Ellingson et al.., 2012 [25] & 358 & ret $^{a}$ & 56.4 & $\mathrm{NA}^{\mathrm{c}}$ & NA & NA & 100 & 36 & 1.1 & 5 \\
\hline Etcheverry et al., 2010 [26] & 50 & $\operatorname{pros}^{a}$ & 57.5 & $N A^{d}$ & NA & 100 & 100 & 60 & 8 & 18 \\
\hline Felsberg et al., 2009 [27] & 66 & $\operatorname{pros}^{\mathrm{a}, \mathrm{b}}$ & 56 & 82 & 100 & 100 & 100 & 39.4 & 0 & 1.5 \\
\hline Gilbert et al.., 2013 [5] & 760 & triala $^{\mathrm{a}, \mathrm{b}}$ & $N A^{e}$ & 100 & 97 & 100 & 100 & 32.1 & 0.8 & 6.7 \\
\hline Hegi et al., 2005 [3] & 106 & trial $^{\mathrm{a}, \mathrm{b}}$ & 56 & 87.3 & 83.8 & 100 & 100 & 43.4 & 1.9 & 10.4 \\
\hline Karayan-Tapon et al., 2010 [28] & 81 & ret $^{a}$ & 61 & 64.2 & NA & 100 & 100 & 67.9 & 0 & 2.5 \\
\hline Lai et al., 2011 [29] & 141 & trial + ret tab $^{a}$ & 58 & 96.1 & 86.2 & 100 & 100 & 40.4 & 0.7 & 7.1 \\
\hline Lakomy et al., 2011 [30] & 38 & $\operatorname{ret}^{\mathrm{a}, \mathrm{b}}$ & 53 & 95 & 100 & 100 & 100 & 31.6 & 2.6 & 7.9 \\
\hline Metellus et al., 2011 [31] & 61 & $\operatorname{pros}^{\mathrm{a}, \mathrm{b}}$ & 59 & 34.4 & 100 & 100 & 100 & 37.7 & 0 & 1.6 \\
\hline Morandi et al., 2010 [32] & 159 & ret $^{a}$ & 57 & 100 & NA & 100 & 100 & 44 & 1.9 & 6.3 \\
\hline Motomura et al., 2011 [33] & 68 & ret $^{a}$ & 55 & 66.2 & NA & 100 & 100 & 33.8 & 1.5 & 2.9 \\
\hline Stupp et al., 2010 [34] & 45 & triala $^{a, b}$ & 57 & 92 & 83 & 100 & 100 & 51.1 & 2.2 & 8.9 \\
\hline Weiler et al., 2010 [35] & 41 & trial $^{\mathrm{b}}$ & 56 & 100 & 90 & 100 & 95.1 & 41 & 0 & 2.4 \\
\hline Weller et al., 2009 [36] & 185 & $\operatorname{pros}^{\mathrm{a}, \mathrm{b}}$ & 61.5 & 84 & 90 & 100 & 100 & 43.8 & 2.7 & 7 \\
\hline \multicolumn{11}{|c|}{ MGMT methylation no prognostic/predictive } \\
\hline Clarke et al., 2009 [10] & 85 & trial & 56.3 & 73 & 78 & 100 & 56.5 & 18.8 & 0 & 4.7 \\
\hline Costa et al., 2010 [11] & 80 & ret & 56 & 53.3 & 90 & 100 & 100 & 47.5 & 6.3 & 23.8 \\
\hline El Hindy et al., 2011 [12] & 160 & ret & 58 & NA & 59.4 & 37.5 & 66.3 & 18.9 & 13.8 & 31.9 \\
\hline Iliadis et al., 2012 [13] & 65 & pros & 59 & 90 & 90.8 & 100 & 35.4 & 43.5 & 1.5 & 7.7 \\
\hline Lam\&Chambers, 2012 [14] & 101 & ret & 56.5 & 47 & 68 & 100 & 100 & 49.5 & 3 & 15.8 \\
\hline Martinez et al., 2009 [15] & 46 & ret & 60.6 & NA & NA & 100 & 100 & 32.6 & 2.2 & 8.7 \\
\hline Mellai et al., 2009 [9] & 67 & ret & 60.3 & NA & 100 & 35 & 100 & 29.9 & 13.4 & 31.3 \\
\hline Schaich et al., 2009 [16] & 63 & ret & 63 & 84 & NA & 100 & 100 & 34.9 & 0 & 4.8 \\
\hline Tang et al., 2012 [17] & 79 & ret & NA & 57 & 100 & 100 & 100 & 32.9 & 5.1 & 15.2 \\
\hline
\end{tabular}

${ }^{a}$, MGMT prognostic for longer overall survival; ${ }^{b}$, MGMT predictive for longer progression-free survival when treated with alkylating drugs; ${ }^{c}$, mean KPS 72.4; ${ }^{d}$, median KPS 78.6. Alkyl, treated with alkylating drugs; ${ }^{\circ}, 26.8 \%$ of patients with age < 50 yrs. Debulk surg: debulking surgery; Meth: Methylated; MGMT: ${ }^{6}$-Methylguanine DNAMethyltransferase; NA: Not Available; Pros: Prospective; PS: Performance Status; Ret: Retrospective

Table 1: Systematic review of studies analyzing the relationship between MGMT methylation and prognosis in glioblastoma patients

\begin{tabular}{|c|c|c|c|c|}
\hline \multirow{2}{*}{ Parameter } & \multicolumn{2}{|c|}{ MGMT promoter methylation } & \multirow{2}{*}{$P$} & \multirow{2}{*}{ OR (95\% Cl) } \\
\hline & Predictive/ prognostic & No predictive/ prognostic & & \\
\hline$N$ cases & 2591 & 746 & NA & NA \\
\hline Retrospective studies (\%) & 45.3 & 79.9 & $<0.0001^{\mathrm{a}}$ & $4.7958(3.946-5.8285)$ \\
\hline Age (yrs) & 57.3 & 58.3 & $0.1894^{b}$ & NA \\
\hline Good PS (\%) & 88.4 & 65.3 & $<0.0001^{\mathrm{a}}$ & $0.2481(0.1971-0.3123)$ \\
\hline Debulking surgery (\%) & 92.6 & 79.6 & $<0.0001^{\mathrm{a}}$ & $0.3115(0.2399-0.4046)$ \\
\hline Treated with alkylating drugs (\%) & 100 & 80.7 & $<0.0001^{\mathrm{a}}$ & $0.0019(0.0003-0.0134)$ \\
\hline MGMT methylated & 40.4 & 34.3 & $0.00617^{a}$ & $0.7699(0.6403-0.9258)$ \\
\hline Deaths at 3 months (\%) & 1.5 & 6 & $<0.0001^{\mathrm{a}}$ & $4.3128(2.7781-6.6954)$ \\
\hline Deaths at 6 months (\%) & 6.9 & 18.1 & $<0.0001^{\mathrm{a}}$ & $2.9952(2.3546-3.8102)$ \\
\hline
\end{tabular}

A: Chi-Square Test; B: Student's $t$ Test; Cl: Confidence Interval; MGMT: O-Methylguanine DNA-Methyltransferase; NA:Not Applicable; OR: Odds Ratio; PS: Performance Status

Table 2: Univariate analysis of clinical data in studies assessing the relationship between MGMT methylation and prognosis.

\begin{tabular}{|c|c|c|c|c|c|c|c|}
\hline Factor & Coeff & SE & Coeff/ SE & $\mathrm{X}^{2}$ value & $P$-value & OR & $95 \% \mathrm{Cl}$ \\
\hline constant & -21.889 & 13.486 & -1.623 & 2.634 & 0.1046 & $3.118 \times 10^{-10}$ & $1.031 \times 10^{-21}-94.322$ \\
\hline$N$ cases & 0.001 & 0.015 & 0.079 & 0.006 & 0.9373 & 1.001 & $0.973-1.030$ \\
\hline median age & 0.322 & 0.223 & 1.445 & 2.089 & 0.1484 & 1.380 & $0.892-2.136$ \\
\hline MGMT methylated cases & 1.953 & 1.440 & 1.356 & 1.839 & 0.1751 & 7.053 & $0.419-118.755$ \\
\hline Retrospective study & 0.907 & 1.171 & 0.775 & 0.601 & 0.4383 & 2.478 & $0.250-24.586$ \\
\hline Treated with alkylating drugs & -5.166 & 3.412 & -1.514 & 2.292 & 0.1300 & 0.006 & $7.101 \times 10^{-6}-4.585$ \\
\hline Deaths at 3 mos & 0.489 & 0.247 & 1.978 & 3.914 & 0.0479 & 1.631 & $1.005-2.648$ \\
\hline
\end{tabular}

Cl: Confidence Interval; Coeff: Coefficient; MGMT: O6-Methylguanine DNA-Methyltransferase; OR: Odds Ratio; SE: Standard Error

Table 3: Multivariate analysis of factors potentially affecting the predictive/prognostic role of MGMT methylation in a study cohort modeled with 3-month death rate. 
Citation: D'Alessandris QG, Montano N, Larocca LM, Maira G, Pallini R (2014) Prognostic Impact of MGMT Promoter Methylation in Glioblastoma - A Systematic Review. J Cancer Sci Ther 6: 136-141. doi:10.4172/1948-5956.1000261

\begin{tabular}{|c|c|c|c|c|c|c|c|}
\hline Factor & Coeff & SE & Coeff/ SE & $x^{2}$ value & $P$-value & OR & $95 \% \mathrm{Cl}$ \\
\hline constant & -36.921 & 20.620 & -1.791 & 3.206 & 0.0734 & $9.234 \times 10^{-17}$ & $2.582 \times 10^{-34}-33.018$ \\
\hline$N$ cases & 0.006 & 0.018 & 0.351 & 0.123 & 0.7256 & 1.006 & $0.971-1.043$ \\
\hline median age & 0.520 & 0.331 & 1.572 & 2.473 & 0.1158 & 1.683 & $0.880-3.220$ \\
\hline MGMT methylated cases & 4.418 & 2.390 & 1.848 & 3.416 & 0.0646 & 82.894 & $0.765-8979.118$ \\
\hline Retrospective study & 0.113 & 1.515 & 0.075 & 0.006 & 0.9406 & 1.120 & $0.057-21.835$ \\
\hline Treated with alkylating drugs & -9.991 & 5.176 & -1.930 & 3.726 & 0.0536 & $4.583 \times 10^{-5}$ & $1.799 \times 10^{-9}-1.167$ \\
\hline Deaths at 6 mos & 0.417 & 0.172 & 2.429 & 5.902 & 0.0151 & 1.517 & $1.084-2.124$ \\
\hline
\end{tabular}

Cl: Confidence Interval; Coeff: Coefficient; Mgmt: $\mathrm{O}^{6}$-Methylguanine Dna-Methyltransferase; OR: Odds Ratio; SE: Standard Error

Table 4: Multivariate analysis of factors potentially affecting the predictive/prognostic role of MGMT methylation in a study cohort modeled with 6-month death rate.

\begin{tabular}{|c|c|c|c|c|}
\hline \multirow{2}{*}{ Authors \& Year } & \multirow{2}{*}{$N$ cases } & \multicolumn{3}{|c|}{ Deaths at 3 months (\%) } \\
\hline & & whole cohort & methylated pts & unmethylated pts \\
\hline \multicolumn{5}{|c|}{ MGMT methylation prognostic/predictive } \\
\hline Balañà et al., 2011 [21] & 70 & 5.7 & 0 & 9.3 \\
\hline Brandes et al., 2008 [22] & 103 & 0 & 0 & 0 \\
\hline Cao et al., 2009 [23] & 73 & 1.4 & 0 & 3.4 \\
\hline Crinière et al., 2007 [24] & 77 & 1.3 & 0 & 3.1 \\
\hline Dunn et al., 2009 [20] & 109 & 3.7 & 3.4 & 3.9 \\
\hline Ellingson et al.., 2012 [25] & 358 & 1.1 & 0 & 1.8 \\
\hline Etcheverry et al., 2010 [26] & 50 & 8 & 6.7 & 10 \\
\hline Felsberg et al., 2009 [27] & 66 & 0 & 0 & 0 \\
\hline Gilbert et al.., 2013 [5] & 760 & 0.8 & 0.8 & 0.8 \\
\hline Hegi et al., 2005 [3] & 106 & 1.9 & 2.2 & 1.7 \\
\hline Karayan-Tapon et al., 2010 [28] & 81 & 0 & 0 & 0 \\
\hline Lai et al., 2011 [29] & 141 & 0.7 & 0 & 1.2 \\
\hline Lakomy et al., 2011 [30] & 38 & 2.6 & 0 & 3.8 \\
\hline Metellus et al., 2011 [31] & 61 & 0 & 0 & 0 \\
\hline Morandi et al., 2010 [32] & 159 & 1.9 & 0 & 3.4 \\
\hline Motomura et al., 2011 [33] & 68 & 1.5 & 0 & 2.2 \\
\hline Stupp et al., 2010 [34] & 45 & 2.2 & 0 & 4.5 \\
\hline Weiler et al., 2010 [35] & 41 & 0 & 0 & 0 \\
\hline Weller et al., 2009 [36] & 185 & 2.7 & 1.2 & 3.8 \\
\hline \multicolumn{5}{|c|}{ MGMT methylation no prognostic/predictive } \\
\hline Clarke et al., 2009 [10] & 85 & 0 & 0 & 0 \\
\hline Costa et al., 2010 [11] & 80 & 6.3 & 5.3 & 7.1 \\
\hline El Hindy et al., 2011 [12] & 160 & 13.8 & NA & NA \\
\hline Iliadis et al., 2012 [13] & 65 & 1.5 & NA & NA \\
\hline Lam\&Chambers, 2011 [14] & 101 & 3 & 4 & 2 \\
\hline Martinez et al., 2009 [15] & 46 & 2.2 & 6.7 & 0 \\
\hline Mellai et al., 2009 [9] & 67 & 13.4 & 10 & 14.9 \\
\hline Schaich et al., 2009 [16] & 63 & 0 & 0 & 0 \\
\hline Tang et al., 2011 [17] & 79 & 5.1 & 3.8 & 5.7 \\
\hline
\end{tabular}

MGMT: $\mathrm{O}^{6}$-methylguanine DNA-methyltransferase; pts: patients

Table 5: Deaths at 3 months according to MGMT status in reviewed studies.

\begin{tabular}{|c|c|c|c|c|}
\hline \multirow{2}{*}{$\begin{array}{l}\text { MGMT promoter } \\
\text { methylation status }\end{array}$} & \multicolumn{2}{|l|}{ Deaths at 3 months (\%) } & \multirow{2}{*}{$\boldsymbol{P}$} & \multirow{2}{*}{ OR $(95 \% \mathrm{Cl})$} \\
\hline & Studies with MGMT methylation prognostic/predictive & Studies with MGMT methylation no prognostic/predictive & & \\
\hline Methylated & 0.8 & 4.4 & 0.0003 & $\begin{array}{l}6.0291(2.2331- \\
16.2776)\end{array}$ \\
\hline Unmethylated & 1.9 & 4.6 & 0.001 & $\begin{array}{l}2.4363(1.2761- \\
4.6516)\end{array}$ \\
\hline
\end{tabular}

Cl: Confidence Interval; MGMT: $\mathrm{O}^{6}$-Methylguanine DNA-Methyltransferase; OR: Odds Ratio

Table 6: Mortality at 3 months according with MGMT status in reviewed studies. 
to identify possible bias of GBM studies focusing on the prognostic/ predictive role of MGMT promoter methylation. We included only studies on at least 30 patients, in order to rule out minor case series. Moreover, to further take into account the power of the study, we included the numerosity of the patients sample among the independent variables of our multivariate analysis. One main result is that in those studies where MGMT promoter methylation was not prognostic/ predictive of better outcome, the patient population showed significantly higher percentages of unfavorable prognosticators, including poor performance status and biopsy surgery, as compared with studies where MGMT promoter methylation was prognostic/ predictive of better outcome. Another important result of our analysis is that studies demonstrating a better prognosis of MGMT methylated cases show significantly lower rates of deaths at 3 and 6 months, and that the 3-month and 6-month death rates are significant independent variables associated with the prognostic value of MGMT promoter methylation.

\section{Interpretation of the findings}

There are several reasons that may explain these results. First of all, the inclusion criteria might differ between studies that demonstrated a prognostic role of MGMT methylation and those studies where MGMT methylation had no prognostic value. Although none of the reviewed studies identified the early deaths as exclusion criteria, some sort of case selection is suggested by the observation that the 3-month mortality rate was significantly lower in the unmethylated cases of MGMT prognostic/predictive studies than in the unmethylated cases of the MGMT no prognostic/predictive studies. Another possible explanation of our results is that the short-term survivors could not complete standard adjuvant treatments, particularly alkylating drugs, which are expected to be more effective in MGMT methylated patients. Results of multivariate analysis showing that MGMT methylation trends to statistical significance if modeled with the 6-month mortality rate but not with the 3-month mortality rate support the concept that a temporal threshold may be necessary in order to demonstrate any clinical benefit of MGMT promoter methylation. Our analysis thereby suggests that the predictive role of MGMT promoter methylation may apply to GBM patients with survival longer than 6 months and should not be extended to the short-term survivors.

\section{Conclusion}

We have identified a possible bias in GBM studies that show a positive predictive/prognostic significance of MGMT promoter methylation, namely the low rate of early deaths. Considering that the present study has been conducted on the limited literature currently available, these results do not warrant a delay in the start of TMZ treatment. However, in the first 6 months from diagnosis of GBM clinicians should be cautious in awarding clinical significance to MGMT promoter methylation.

\section{The authors have no conflict of interest to disclose.}

\section{Acknowledgements}

This work was supported by Fondi d'Ateneo Università Cattolica del Sacro Cuore, Linea D.1, and by a donation from Carmela Libro, to RP.

\section{References}

1. Esteller M, Garcia-Foncillas J, Andion E, Goodman SN, Hidalgo OF, et al. (2000) Inactivation of the DNA-repair gene MGMT and the clinical response of gliomas to alkylating agents. N Engl J Med 343: 1350-1354.
2. Watts GS, Pieper RO, Costello JF, Peng YM, Dalton WS, et al. (1997) Methylation of discrete regions of the O6-methylguanine DNA methyltransferase (MGMT) CpG island is associated with heterochromatinization of the MGMT transcription start site and silencing of the gene. Mol Cell Biol 17: 5612-5619.

3. Hegi ME, Diserens AC, Gorlia T, Hamou MF, de Tribolet N, et al. (2005) MGMT gene silencing and benefit from temozolomide in glioblastoma. $\mathrm{N}$ Engl $\mathrm{J}$ Med 352: 997-1003.

4. Stupp R, Hegi ME, Mason WP, van den Bent MJ, Taphoorn MJ, et al. (2009) Effects of radiotherapy with concomitant and adjuvant temozolomide versus radiotherapy alone on survival in glioblastoma in a randomised phase III study: 5-year analysis of the EORTC-NCIC trial. Lancet Oncol 10: 459-466.

5. Gilbert MR, Wang M, Aldape KD, Stupp R, Hegi ME, et al. (2013) Dose-dense temozolomide for newly diagnosed glioblastoma: a randomized phase III clinical trial. J Clin Oncol 31: 4085-4091.

6. Sciuscio D, Diserens AC, van Dommelen K, Martinet D, Jones G, et al. (2011) Extent and patterns of MGMT promoter methylation in glioblastoma- and respective glioblastoma-derived spheres. Clin Cancer Res 17: 255-266.

7. Shah N, Lin B, Sibenaller Z, Ryken T, Lee H, et al. (2011) Comprehensive analysis of MGMT promoter methylation: correlation with MGMT expression and clinical response in GBM. PLoS One 6: e16146.

8. Lalezari S, Chou AP, Tran A, Solis OE, Khanlou N, et al. (2013) Combined analysis of O6-methylguanine-DNA methyltransferase protein expression and promoter methylation provides optimized prognostication of glioblastoma outcome. Neuro Oncol 15: 370-381.

9. Mellai M, Caldera V, Annovazzi L, Chiò A, Lanotte M, et al. (2009) MGMT promoter hypermethylation in a series of 104 glioblastomas. Cancer Genomics Proteomics 6: 219-227.

10. Clarke JL, Iwamoto FM, Sul J, Panageas K, Lassman AB, et al. (2009) Randomized phase II trial of chemoradiotherapy followed by either dose-dense or metronomic temozolomide for newly diagnosed glioblastoma. J Clin Oncol 27: 3861-3867.

11. Costa BM, Caeiro C, Guimarães I, Martinho O, Jaraquemada T, et al. (2010) Prognostic value of MGMT promoter methylation in glioblastoma patients treated with temozolomide-based chemoradiation: a Portuguese multicentre study. Oncol Rep 23: 1655-1662.

12. El Hindy N, Bachmann HS, Lambertz N, Adamzik M, Nückel H, et al. (2011) Association of the $\mathrm{CC}$ genotype of the regulatory BCL2 promoter polymorphism $(-938 \mathrm{C}>\mathrm{A})$ with better 2-year survival in patients with glioblastoma multiforme. J Neurosurg 114: 1631-1639.

13. Iliadis G, Kotoula V, Chatzisotiriou A, Televantou D, Eleftheraki AG, et al (2012) Volumetric and MGMT parameters in glioblastoma patients: survival analysis. BMC Cancer 12: 3.

14. Lam N, Chambers CR (2012) Temozolomide plus radiotherapy for glioblastoma in a Canadian province: efficacy versus effectiveness and the impact of O6methylguanine-DNA-methyltransferase promoter methylation. J Oncol Pharm Pract 18: 229-238.

15. Martinez R, Martin-Subero JI, Rohde V, Kirsch M, Alaminos M, et al. (2009) A microarray-based DNA methylation study of glioblastoma multiforme. Epigenetics 4: 255-264.

16. Schaich M, Kestel L, Pfirrmann M, Robel K, Illmer T, et al. (2009) A MDR1 (ABCB1) gene single nucleotide polymorphism predicts outcome of temozolomide treatment in glioblastoma patients. Ann Oncol 20: 175-181.

17. Tang K, Jin Q, Yan W, Zhang W, You G, et al. (2012) Clinical correlation of MGMT protein expression and promoter methylation in Chinese glioblastoma patients. Med Oncol 29: 1292-1296.

18. Zawlik I, Vaccarella S, Kita D, Mittelbronn M, Franceschi S, et al. (2009) Promoter methylation and polymorphisms of the MGMT gene in glioblastomas: a population-based study. Neuroepidemiology 32: 21-29.

19. Stupp R, Mason WP, van den Bent MJ, Weller M, Fisher B, et al. (2005) Radiotherapy plus concomitant and adjuvant temozolomide for glioblastoma. N Engl J Med 352: 987-996.

20. Dunn J, Baborie A, Alam F, Joyce K, Moxham M, et al. (2009) Extent of MGMT promoter methylation correlates with outcome in glioblastomas given temozolomide and radiotherapy. $\mathrm{Br} \mathrm{J}$ Cancer 101: 124-131.

21. BalaÅ,a C, Carrato C, RamÃrez JL, Cardona AF, Berdiel M, et al. (2011) 
Citation: D'Alessandris QG, Montano N, Larocca LM, Maira G, Pallini R (2014) Prognostic Impact of MGMT Promoter Methylation in Glioblastoma - A Systematic Review. J Cancer Sci Ther 6: 136-141. doi:10.4172/1948-5956.1000261

Tumour and serum MGMT promoter methylation and protein expression in glioblastoma patients. Clin Transl Oncol 13: 677-685

22. Brandes AA, Franceschi E, Tosoni A, Blatt V, Pession A, et al. (2008) MGMT promoter methylation status can predict the incidence and outcome of pseudoprogression after concomitant radiochemotherapy in newly diagnosed glioblastoma patients. J Clin Oncol 26: 2192-2197.

23. Cao VT, Jung TY, Jung S, Jin SG, Moon KS, et al. (2009) The correlation and prognostic significance of MGMT promoter methylation and MGMT protein in glioblastomas. Neurosurgery 65: 866-875.

24. Crinière E, Kaloshi G, Laigle-Donadey F, Lejeune J, Auger N, et al. (2007) MGMT prognostic impact on glioblastoma is dependent on therapeutic modalities. J Neurooncol 83: 173-179.

25. Ellingson BM, Cloughesy TF, Pope WB, Zaw TM, Phillips H, et al. (2012) Anatomic localization of O6-methylguanine DNA methyltransferase (MGMT) promoter methylated and unmethylated tumors: a radiographic study in 358 de novo human glioblastomas. Neuroimage 59: 908-916.

26. Etcheverry A, Aubry M, de Tayrac M, Vauleon E, Boniface R, et al. (2010) DNA methylation in glioblastoma: impact on gene expression and clinical outcome. BMC Genomics 11: 701.

27. Felsberg J, Rapp M, Loeser S, Fimmers R, Stummer W, et al. (2009) Prognostic significance of molecular markers and extent of resection in primary glioblastoma patients. Clin Cancer Res 15: 6683-6693.

28. Karayan-Tapon L, Quillien V, Guilhot J, Wager M, Fromont G, et al. (2010) Prognostic value of O6-methylguanine-DNA methyltransferase status in glioblastoma patients, assessed by five different methods. J Neurooncol 97 311-322.

29. Lai A, Tran A, Nghiemphu PL, Pope WB, Solis OE, et al. (2011) Phase I study of bevacizumab plus temozolomide during and after radiation therapy for patients with newly diagnosed glioblastoma multiforme. J Clin Oncol 29 142-148.

30. Lakomy R, Sana J, Hankeova S, Fadrus P, Kren L, et al. (2011) MiR-195 miR-196b, miR-181c, miR-21 expression levels and O-6-methylguanine-DNA methyltransferase methylation status are associated with clinical outcome in glioblastoma patients. Cancer Sci 102: 2186-2190.

31. Metellus P, Nanni-Metellus I, Delfino C, Colin C, Tchogandjian A, et al. (2011) Prognostic impact of CD133 mRNA expression in 48 glioblastoma patients treated with concomitant radiochemotherapy: a prospective patient cohort at a single institution. Ann Surg Oncol 18: 2937-2945.

32. Morandi L, Franceschi E, de Biase D, Marucci G, Tosoni A, et al. (2010) Promoter methylation analysis of O6-methylguanine-DNA methyltransferase in glioblastoma: detection by locked nucleic acid based quantitative PCR using an imprinted gene (SNURF) as a reference. BMC Cancer 10: 48.

33. Motomura K, Natsume A, Kishida Y, Higashi H, Kondo Y, et al. (2011) Benefits of interferon- $\hat{I}^{2}$ and temozolomide combination therapy for newly diagnosed primary glioblastoma with the unmethylated MGMT promoter: A multicenter study. Cancer 117: 1721-1730.

34. Stupp R, Hegi ME, Neyns B, Goldbrunner R, Schlegel U, et al. (2010) Phase I/lla study of cilengitide and temozolomide with concomitant radiotherapy followed by cilengitide and temozolomide maintenance therapy in patients with newly diagnosed glioblastoma. J Clin Oncol 28: 2712-2718.

35. Weiler M, Hartmann C, Wiewrodt D, Herrlinger U, Gorlia T, et al. (2010) Chemoradiotherapy of newly diagnosed glioblastoma with intensified temozolomide. Int J Radiat Oncol Biol Phys 77: 670-676.

36. Weller M, Felsberg J, Hartmann C, Berger H, Steinbach JP, et al. (2009) Molecular predictors of progression-free and overall survival in patients with newly diagnosed glioblastoma: a prospective translational study of the German Glioma Network. J Clin Oncol 27: 5743-5750. 